\title{
Taxonomia XBRL-SPED: Simplificação e Auditoria no âmbito do Sistema Público de Escrituração Digital (SPED)
}

\section{Title: XBRL- SPED Taxonomy: Simplification and Audit under the Public Digital Bookkeeping System (SPED)}

\author{
José Geraldo Luciano', Paulo Caetano da Silva ${ }^{1}$, Clovis Belbute Peres ${ }^{2}$ \\ Unifacs - Universidade Salvador - Laureate International Universities \\ Salvador - Bahia - Brasil \\ Abracicon - Academia Brasileira de Ciências Contábeis \\ Distrito Federal - Brasilia - Brasil \\ jgeraldoluciano@gmail.com, paulo.caetano@unifacs.br, \\ clovisbperes@gmail.com
}

\begin{abstract}
Companies need financial and non-financial data that possess credibility, reliability, integrity and availability for decision-making processes. To extract and process data from different sources is not a trivial task. The Public Digital Bookkeeping System - SPED, managed by the Secretariat of the Brazilian Federal Revenue has brought gains, but still presents complexities, interoperability challenges and relatively low standardization, implying multiplicity of representation of concepts in its component projects. This work brings investigation on simplification and harmonization challenges. XBRL GL taxonomy contributes to the standardization and support audit methods and continuous monitoring. This paper proposes a data model based on XBRL GL for SPED projects. In nine SPED projects, there was a decrease from 5,065 to 1,213 representations.
\end{abstract}

Keywords. SPED, XBRL GL, XBRL-SPED Taxonomy, Financial Data Standardization.

Resumo. Empresas necessitam de dados financeiros e não financeiros que possuam credibilidade, confiabilidade, integridade e disponibilidade para os processos decisórios. Extrair e processar dados de fontes diversas não é trivial. O Sistema Público de Escrituração Digital - SPED da Secretaria da Receita Federal do Brasil, embora tenha trazido ganhos, ainda apresenta complexidades e desafios de interoperabilidade e de padronização do formato de dados, implicando em multiplicidade de representação de conceitos nos seus projetos. Este trabalho traz uma abordagem de simplificação e harmonização. A taxonomia XBRL GL contribui para a padronização e apoia os métodos de auditoria e monitoramento contínuo. Um modelo de dados baseado em XBRL GL é apresentado para o SPED objetivando aumentar a simplificação e padronização sobre os conceitos existentes. Em nove projetos do SPED houve uma redução de 5.065 para 1.213 representações. 
Palavras-Chave. SPED, XBRL GL, Taxonomia XBRL-SPED, Padronização de Dados Financeiros.

\section{Introduction}

As últimas décadas do século XX foram marcadas pelo que se denominou de a Terceira Revolução Tecnológica. Ela caracterizou-se pelos avanços nas tecnologias da informação e comunicação, promovendo o surgimento de uma economia fundamentada no conhecimento, denominada de Era do Conhecimento, e na informação. A inovação e difusão tecnológica tornaram-se elementos essenciais para o desenvolvimento. Neste contexto, a globalização é consequência da tecnologia da informação. Logo, numa economia globalizada empresas precisam ser mais ágeis e dinâmicas consumindo tecnologia e estimulando a pesquisa e o desenvolvimento de novas tecnologias (Guimarães e Johnson, 2007, p.12-13).

Apoiadas no desenvolvimento tecnológico as empresas começaram a concorrer igualitariamente no ambiente globalizado, no qual a eficiência, eficácia e agilidade são pilares para se perpetuarem no mercado e, consequentemente, obter sucesso. As atuais tecnologias disponíveis têm condições de suportar procedimentos e métodos que garantam informações cruciais para que uma empresa possa direcionar suas ações. Consequentemente, os empreendimentos empresariais, recursos humanos e tecnológicos necessitam contínua adequação às exigências do mercado. Da mesma forma, identificar, armazenar e processar informações é essencial para se ter uma base de dados íntegra para a tomada de decisões.

As organizações, independentemente do ramo de atividade e setor econômico, têm sido pressionadas a agir de forma transparente. Para Ballou, Heitger e Landes (2006), essa pressão tem conduzido ao aumento da divulgação das suas práticas, através da publicação de relatórios sobre o seu desempenho social, ambiental e econômico. Elaborar relatórios consiste em medir, divulgar e prestar contas, às várias partes interessadas, sobre a estratégia, abordagem de gestão e o desempenho das organizações. Neste contexto, as empresas têm procurado auditar os seus relatórios com o objetivo de analisar se estes transmitem de forma transparente os valores e princípios corporativos, as práticas de gestão e o desempenho da empresa. Atualmente, governos, investidores e a sociedade exigem transparência e confiabilidade nas informações prestadas pelas empresas. Os responsáveis pela elaboração dos relatórios utilizam diversos tipos de abordagem para implementar um processo externo de verificação incluindo a utilização de revisores oficiais, grupos constituídos por stakeholders (partes interessadas) ou indivíduos não pertencentes à organização.

Portanto, há a necessidade da utilização de ferramentas que possam auxiliar neste processo, garantindo assim a fiabilidade das informações que são divulgadas. A Auditoria Contínua é uma dessas ferramentas, a qual pode ser definida como "qualquer método utilizado por auditores para executar atividades relacionadas com auditoria de uma forma mais contínua ou de forma contínua" (Coderre, 2005); ou, ainda, como "um tipo de auditoria que produz resultados simultaneamente ou em um pequeno período após a ocorrência de um evento relevante" (Vasarhelyi e Halper, 1991).

No Brasil, as estruturas governamentais de controle alcançaram benefícios significativos com a utilização da tecnologia da informação. Paralelamente ao desenvolvimento tecnológico empresarial, ao longo de décadas, os órgãos de controle 
implementaram mecanismos que permitiram um maior e melhor controle sobre as empresas. Desta forma, passaram a monitorar as empresas com maior eficiência através de um controle mais efetivo sobre as operações mercantis, as apurações dos impostos e a prestação de contas. Consequentemente, alcançaram uma maior qualidade das informações que são disponibilizadas através das informações prestadas pelas empresas. O fato importante desta inovação ocorreu no ano de 2007 com a institucionalização do projeto Sistema Público de Escrituração Digital (Portal SPED, 2014), mais conhecido pelo seu acrônimo SPED, que provocou uma mudança significativa na relação entre as entidades governamentais e entidades empresariais. O SPED é um sistema público que engloba diversas iniciativas, órgãos do governo e tecnologias. O SPED foi criado por meio de um Decreto Federal (Decreto $n^{\circ}$ 6.022, de 22 de janeiro de 2007) e se tornou uma obrigação aos negócios feitos no Brasil. A partir da instituição do SPED foram realizados diversos projetos para implementação de sistemas de informação que atendam aos requisitos da legislação. Peres (2015) traz uma exposição didática e concisa do projeto SPED, ressaltando a inovação que ele aportou à ciência contábil.

O SPED estabeleceu uma nova forma de envio de informações para as entidades reguladoras e fiscais. Sua implantação trouxe inúmeros benefícios: redução de papel e, consequente, redução do custo de armazenamento; rapidez no acesso às informações; simplificação de controles, agilização de processos e aumento da produtividade das entidades reguladoras; e, melhoria na qualidade da informação (Portal SPED, 2014). O projeto SPED provocou mudanças nas relações entre as empresas contribuintes, escritórios contábeis, desenvolvedoras de software e entidades governamentais (Geron, 2011). Nesse cenário, a maioria das empresas assume a responsabilidade pela geração, validação e transmissão dos arquivos em substituição a muitos escritórios contábeis que enfrentavam dificuldades tecnológicas para realizar tais tarefas em função da quantidade de dados a ser processada. A adoção de requisitos que envolvem a qualidade da informação é crucial para que se possa reduzir os riscos das autuações. Neste contexto, critérios como transparência, confiabilidade, coerência e a validação das informações são tópicos de extrema relevância no ambiente do SPED.

O projeto SPED é composto por vários projetos que foram concebidos gradualmente. Por isso, cada projeto teve um modelo conceitual próprio que objetivou atender a uma demanda especifica. Há projetos que foram implementados a partir de um modelo de dados especificado no padrão XML e outros projetos que utilizam o padrão ASCII. Desta forma, esses projetos não podem estabelecer uma comunicação direta entre si. A existência de modelos de dados distintos, mesmo usando apenas duas tecnologias para representá-los (XML e ASCII), causou repetição de conceitos com representações distintas (tags e campos), seja entre os projetos ou internamente a cada modelo conceitual. Destarte, a repetição na representação de conceitos provocou baixa padronização. Isto revela desafios que merecem atenção especial: pouca interoperabilidade ${ }^{1}$ entre os projetos do SPED e demais sistemas governamentais; aumento no custo da manutenção dos

\footnotetext{
${ }^{1}$ Entende-se por interoperabilidade "como uma característica que se refere à capacidade de diversos sistemas e organizações trabalharem em conjunto (interoperar) de modo a garantir que pessoas, organizações e sistemas computacionais interajam para trocar informações de maneira mais eficaz e eficiente" http://www.governoeletronico.gov.br/acoes-e-projetos/e-ping-padroes-deinteroperabilidade/o-que-eInteroperabilidade.
} 
sistemas; aumento no tempo de implementação de novas rotinas; e, necessidade de desenvolvimento de interfaces entre os projetos. Embora a adoção do SPED tenha facilitado o controle governamental, a atual estrutura, tal qual qualquer camada extra de controle, não é isenta de custos, os quais se deve buscar reduzir ou evitar. O SPED proporcionou redução de custos para as empresas e governo, por exemplo, com a necessidade de gerar documentação em papel e automatização dos procedimentos fiscalizatórios, reduzindo com isso, o que é denominado "custo Brasil", todavia, ainda há muito a ser simplificado.

O termo padronização é largamente discutido em todas as esferas organizacionais (públicas e privadas) quando surge a necessidade de alcançar mecanismos eficientes e eficazes que garantam requisitos de transparência, produtividade, adaptabilidade, flexibilidade, confiabilidade e interoperabilidade. Segundo Kuenkaikaew and Vasarhelyi (2013) "as empresas precisam mais do que apenas auditorias de demonstrações financeiras. Elas precisam de segurança em um conjunto mais amplo de informações de negócios. Portanto, os auditores devem considerar a necessidade de captação de métodos analíticos modernos e a aceleração e automação da tecnologia da informação empresarial". Entretanto, essa necessidade só pode ser atendida dentro de um ambiente organizacional padronizado e com uma alta interoperabilidade.

A análise feita sobre a estrutura de representação de dados dos projetos do SPED permitiu identificar novos desafios a serem superados. Levando-se em consideração que os arquivos transacionais (XML e ASCII) representam a fronteira entre o fisco e os contribuintes, seria oportuno que eles pudessem ser auditados antes de sua transmissão aos órgãos reguladores e fiscalizadores. Portanto, algumas perguntas emergem dessas constatações: como implementar uma rotina de auditoria em tempo real, de baixa complexidade, em arquivos que apresentam estruturas divergentes? Como desenvolver métodos de extração, análise e validação de informações em arquivos que apresentam conceitos repetidos? Como realizar levantamentos de dados tomando por fonte de dados arquivos transacionais de projetos diferentes?

A necessidade de aumentar a padronização no SPED, os ganhos advindos desse esforço de padronização e a ausência de trabalhos acadêmicos com ênfase nestas questões apresentadas acima são as motivações para este trabalho. Para um projeto da magnitude do SPED, que tem suas informações básicas ${ }^{2}$ alicerçadas em plataforma XML, é extremamente importante a substituição do padrão ASCII para o padrão XML. No entanto, a adoção da tecnologia XBRL, em substituição ao padrão XML e ASCII, tem o potencial de posicionar o projeto SPED num padrão internacionalmente reconhecido que busca a transparência, a integridade e a qualidade das informações intercambiadas entre as organizações, órgãos governamentais reguladores e entidades financeiras.

Cabe ressaltar que as crises internacionais de grandes repercussões ocorridas em $2001^{3}$ e $2002^{4}$, motivadas por fraudes fiscais, reforçaram o sentimento de perda de

\footnotetext{
${ }^{2}$ Informações oriundas dos projetos NF-e, NFS-e e CT-e baseados na plataforma XML que suprem os demais projetos do SPED.

${ }^{3}$ Enron, companhia elétrica Americana causou graves perdas econômicas aos investidores http://www.bbc.co.uk/portuguese/pulltogether/s_enron.shtml

${ }^{4}$ Global Crossing, Xerox, Tyco, Worldcom e Merck apresentaram receitas contabilizadas que de fato nunca existiram -
} 
confiança nas práticas contábeis. Alguns outros acontecimentos ocorridos entre os anos de 1975 e 2001 fizeram surgir leis e as regulamentações que as empresas tiveram que seguir, como a quebra do Banco Herstaff da Alemanha em 1975; a falência em meios a fraudes e lavagem de dinheiro do Bank of Credit Commerce International em 1993; a falência após 233 anos de existência do Banco Barings e; a quebra da sétima maior empresa dos EUA, a Enron, que faliu em 2001, demitindo mais de 20.000 funcionários (Guerra, 2007). Com o objetivo de evitar a repetição dos problemas relacionados às fraudes contábeis, ocorridas nesse período, foram criadas em diversos países leis e regulamentações para permitir aos governos locais um melhor controle e monitoramento das organizações, e consequente aumento da credibilidade das empresas e maior segurança ao mercado financeiro. Dentre elas, está a lei Sarbanes-Oxley (SOX) que foi criada em 2002, pelo congresso Americano e afetou diretamente a forma como as empresas apresentariam seus relatórios financeiros, principalmente, as de capital aberto que possuíam ações na bolsa de valores americana (SARBANES-OXLEY, 2002). Com requerimentos de controles contábeis e financeiros rigorosos e com o aumento da responsabilização dos gestores, as empresas deveriam estabelecer políticas, regras e procedimentos auditáveis para gerir e controlar seus processos, registros documentais e divulgar seus resultados.

Essas crises motivaram a adoção do padrão XBRL como a tecnologia viável para evitar fraudes fiscais já que proporciona maior transparência aos investidores. O padrão XBRL tem a capacidade de viabilizar a apresentação de todo o conteúdo informacional numa disposição que facilita uma comparação imediata dos documentos que dão origem à informação intercambiada. A tecnologia XBRL permite reduzir o redirecionamento da informação na medida em que consegue extrair conteúdo dos mais diversos formatos e fontes de dados (banco de dados, textos, planilhas etc.). Outro fator importante é a extensibilidade da tecnologia que permite o reuso de conceitos e a inserção de novos elementos de acordo com as exigências de um respectivo negócio. A padronização do projeto SPED é imprescindível para que possa promover a auditoria contínua dos documentos e da base de dados favorecendo um controle mais efetivo sobre as informações.

Este trabalho fornece uma abordagem sobre a padronização de um modelo de dados, alicerçada na taxonomia XBRL GL, para o SPED. Esse modelo de dados visa: aumentar a padronização do SPED; a eliminação da multiplicidade de conceitos; viabilização dos processos de auditoria e monitoramento contínuos, tanto para as empresas, quanto para os órgãos reguladores. Ademais, propicia maior qualidade das informações que serão geradas e compartilhadas entre as entidades governamentais e empresariais.

Esse artigo é composto por quatro seções. A segunda seção é destinada à fundamentação teórica sobre a tecnologia XBRL. Em seguida, na terceira seção, é apresentada uma proposta de padronização do SPED por meio de XBRL GL a fim de facilitar o processo de auditoria continua. Por fim, na quarta seção, são colocadas as conclusões deste trabalho seguidas das referências bibliográficas.

http://www.bndes.gov.br/SiteBNDES/export/sites/default/bndes_pt/Galerias/Arquivo/conhecimento/r evista/rev1802.pdf 


\section{Conceitos relevantes para a compreensão do trabalho}

Esta seção apresenta uma revisão dos conceitos mencionados no texto fazendo uma abordagem sobre XBRL, enfatizando a taxonomia XBRL GL, e tipos de auditoria.

\subsection{XBRL}

Em 1998, a linguagem XML (eXtensible Markup Language) foi recomendada pelo W3C, World Wide Web Consortium, na tentativa de resolver os problemas e as limitações das SGML e HTML. De acordo com a W3C (2008), trata-se de uma linguagem de formato simples e flexível destinada para os intercâmbios de publicações eletrônicas e de uma variedade de tipos de dados na internet e em outros ambientes computacionais. Segundo Silva, Silva e Junior (2006, p.15), "a XML permite que usuários adicionem estrutura a seus documentos, mas quem for usá-los terá de saber o significado dessa estrutura para que possa criar os sistemas de informação que irão processá-los". Malhotra and Garritt (2004, p. 62) a define como uma metalinguagem para classificação, compreensão e gerenciamento de dados.

Em 1998, Charles Hoffman pesquisou a utilização da tecnologia XML no intercâmbio eletrônico de informações financeiras através de relatórios, obtendo apoio da AICPA (American Institute of Certified Public Accountants). Denominada, anteriormente, por XFRML (eXtensible Financial Reporting Markup Language), passou a chamar XBRL (eXtensible Business Reporting Language), "em meados de 1999, quando se decidiu aumentar o seu escopo para relatórios de negócio, com a criação do consórcio para o desenvolvimento da especificação" (Silva et al., 2006, p.32). A especificação XBRL 2.1 é composta por dois componentes principais, isto é, a taxonomia e o instance document. A taxonomia contém a descrição e classificação de negócio e os termos financeiros. O instance document contém os fatos, isto é, contém os dados financeiros assim como a descrição de seus elementos contextuais. Uma ou mais taxonomias poderão ser aplicadas a um único instance document. A taxonomia e o instance document compõem os documentos XBRL. O instance document, i.e. o documento de instância, é o relatório financeiro e a taxonomia contém as descrições semânticas e sintáticas dos elementos que compõem o relatório. Silva et al. (2006, p.32) afirma que "a linguagem XBRL foi desenvolvida para a preparação e intercâmbio de dados financeiros, fornecendo uma estrutura baseada em XML para uso na criação, intercâmbio e análise de demonstrações contábeis ou financeiras, especificamente para a área contábil, incluindo, mas não se limitando a demonstrações contábeis, análises de auditoria, entre outros". A linguagem XBRL define a estrutura básica dos documentos de instância, os que portam os dados, e especifica como taxonomias podem ser criadas para acomodar particularidades de cada organização por meio da introdução de novos elementos, denominados conceitos. A possibilidade de estender a linguagem é uma característica que possibilita a ampliação de seu uso (Dunce, Silva e Viana, 2013).

Sobre a adoção de XBRL Riccio et al. (2006) discorre:

XBRL vai desempenhar um papel essencial na obtenção de transparência empresarial e vai aumentar exponencialmente a velocidade com que os investidores podem obter e analisar a informação (Dipiazza e Eccles, 2004, p.3). 
Segundo Silva et al. (2006), as vantagens de divulgação de informações pela internet, utilizando a tecnologia XBRL, são:

- Padronização no formato dos dados;

- Facilidade de intercâmbio de informações;

- Eliminação de conversão frequente de dados

- Maior transparência em virtude da divulgação pela internet;

- Facilidade de recuperação e utilização dos dados;

- Maior confiabilidade proporcionada aos analistas da informação;

- Possibilidade de integração na cadeia de suprimentos dos dados financeiros;

- Eliminação da redundância no fornecimento dos dados;

- Redução de erros;

- Redução do tempo de análise;

- Possibilidade de adaptações, por ser um padrão aberto;

- Aparente redução de custos gerais.

Uma taxonomia XBRL é composta por esquemas, que definem os elementos XML para representarem os conceitos financeiros e contábeis, e por linkbases, que estabelecem os relacionamentos semânticos entre esses elementos. Um esquema da taxonomia é um documento definido a partir da tecnologia XML Schema e os linkbases são documentos XML que seguem a especificação XLink do W3C. Os linkbases originais da especificação XBRL 2.1 são cinco. Os linkbases calculation, presentation e definition são responsáveis por estabelecer o relacionamento entre os elementos da taxonomia. Os linkbases label e reference determinam o relacionamento entre os elementos e o documento de instância (Instance document). Os documentos de instância são aqueles que informam os dados, i.e o relatório financeiro/contábil.

Há dois tipos relevantes de taxonomia XBRL: a XBRL Global Ledger (XBRL GL) e a XBRL Financial Reporting (XBRL FR). A taxonomia XBRL GL permite a representação de informações encontradas em um plano de contas, e.g. lançamentos contábeis ou transações históricas, financeiras e não financeiras. As taxonomias XBRL FR são explicitamente projetadas para promover comunicações, isto é, relatórios financeiros para serem divulgados externamente e internamente pelas organizações. Amrhein, Farewell and Pinsker (2009) afirmam que um "O benefício significativo oferecido pelo XBRL (tanto FR quanto GL) é que a tecnologia fornece um método para expressar o significado semântico e um meio para validar o conteúdo de um documento de instância contra esse significado semântico, baseado em relacionamentos definidos pela taxonomia. XBRL GL oferece a capacidade de validar regras e fórmulas empresariais em vários níveis dentro da organização”.

\subsection{Taxonomia XBRL GLOBAL LEDGER (XBRL GL)}

A taxonomia XBRL GL foi criada a partir da especificação XBRL 2.1. Enquanto a tecnologia XBRL enfatiza a preparação e intercâmbio de dados financeiros e análise de demonstrações financeiras ou contábeis, a taxonomia XBRL GL, segundo Garbelloto (2006, p. 59) é um formato padrão para representar dados financeiros e não financeiros no nível de detalhe, mover os dados entre diferentes sistemas e aplicações, e fornecer o contexto para aprofundar o conhecimento a partir de relatórios de resumo (XBRL FR) para o detalhe dos dados a que se relaciona. 

principais:

Segundo Luciano e Silva (2014), apresentam-se como suas características

- Proporcionar um formato normalizado para a representação dos campos de dados que se encontram na contabilidade;

- É um plano de contas independente, permitindo a representação de qualquer conceito que se encontra em um plano de contas, lançamentos diários de transações históricas, financeiras e não financeiras;

- Permite a consolidação da informação;

- Os módulos da taxonomia incluem arquivos schema (.xsd), arquivos linkbases e de apresentação (.xml);

- Está completamente integrada à cadeia de suprimento da informação financeira, normaliza a apresentação dos dados financeiros e melhora a qualidade da informação disponível para a tomada de decisão.

XBRL GL facilita a movimentação eficiente de dados de negócios e contabilidade, entre aplicações de software, contribuindo para a interoperabilidade e integração. Desta forma apuram-se os seguintes benefícios:

- Elimina o retrabalho;

- Melhoria no sistema de controle interno;

- Melhora a comunicação entre os sistemas e as pessoas;

- Facilita negócio transacional com diferentes padrões baseados em XML, e estabelece uma correspondência eficaz entre cada uma das aplicações e os sistemas de contabilidade;

- Facilita a forma de representar a informação contida nas aplicações de contabilidade para a transferência, registro e auditoria de dados de uma forma padronizada;

- Contribui para o acesso a dados detalhados subjacentes em um relatório XBRL FR (XBRL Financial Reporting);

- É uma ferramenta eficaz para auditoria contínua.

Amrhein et al. (2009) afirmam que a "XBRL GL tem o potencial de alterar a forma como as informações são consolidadas e compartilhadas dentro de uma organização e ao longo da cadeia de fornecimento de informações financeiras. Consequentemente, tem o potencial de fornecer suporte para relatórios financeiros e ao processo de auditoria, atuando como um catalisador para a mudança nessas áreas. As organizações que adotam XBRL GL são susceptíveis de obter benefícios estratégicos alavancando as suas relações comerciais". Entretanto, é importante mostrar algumas diferenças entre as tecnologias GL e FR.

Os relatórios financeiros baseiam-se na taxonomia XBRL FR, na qual cada elemento da taxonomia identifica um conceito de informação financeira. O XBRL GL é uma ligação entre os sistemas de registros contábeis, no seu nível de maior granularidade dos dados, e os relatórios financeiros, no mais alto nível de agregação (menor granularidade dos dados). 
Os objetivos do XBRL GL diferem daqueles do XBRL FR. Enquanto a primeira taxonomia tem como propósito representar as informações contábeis mais básicas, taxonomias FR representam os relatórios resultantes das contas básicas representadas pela XBRL GL (Amrhein et al., 2009). Confrontando as duas taxonomias verificam-se as seguintes características individuais (Luciano e Silva, 2014), no Quadro 1.

\begin{tabular}{|c|c|}
\hline XBRL GL & XBRL FR \\
\hline $\begin{array}{l}\text { - Projetada para obter detalhes } \\
\text { associados às transações. } \\
\text { - Geralmente, é um relatório interno } \\
\text { envolvendo divulgação dentro da } \\
\text { empresa ou entidades próximas. } \\
\text { - Representa os registros individuais de } \\
\text { um sistema financeiro ou contábil. }\end{array}$ & $\begin{array}{l}\text { Desenvolvido principalmente para } \\
\text { representar relatórios de valores } \\
\text { agregados, segmentação, } \\
\text { especialmente para órgãos } \\
\text { reguladores. } \\
\text { - Geralmente para a comunicação } \\
\text { externa, divulgar informações a } \\
\text { outros. } \\
\text { - Representa a informação agregada } \\
\text { por um período ou momento de } \\
\text { tempo. }\end{array}$ \\
\hline
\end{tabular}

\section{Quadro 1: Comparação entre as taxonomias XBRL GL e FR}

\subsection{Auditoria}

Nesta seção faz-se uma apresentação de conceitos importantes sobre o tema abordando aspectos sobre as auditorias tradicionais, auditoria contínua, auditoria preventiva e preditiva.

As auditorias tradicionais são aquelas que, após a concretização do fato, apresentam relatórios demonstrando suas repercussões. Além de ser um processo lento, as auditorias não acompanham o dinamismo das empresas e do mercado em que atuam. Há um descompasso entre a ocorrência do fato e a tomada de decisão. A tomada de decisão em muitas situações é feita tardiamente impedindo, desta forma, que o aumento de custos, perda de produtividade e consequente perda de vantagem competitiva sejam evitados. Esse cenário ocorre em função de que muitos dos procedimentos de autoria são realizados manualmente e contemplando uma limitada amostra de dados (Kuenkaikaew e Vasarhelyi, 2013). Ao trabalhar com dados históricos, as auditorias tradicionais focam no passado para projetar o futuro. Desta forma, a capacidade de a empresa atuar proativamente fica comprometida. Segundo Kuenkaikaew e Vasarhelyi (2013),

as empresas precisam mais do que apenas auditorias de demonstrações financeiras. Elas precisam de segurança em um conjunto mais amplo de informações de negócios. Portanto, os auditores devem considerar a necessidade de captação de métodos analíticos modernos e a aceleração e automação da tecnologia da informação empresarial (tradução própria).

A auditoria continua permite que a empresa disponha de informação oportuna e confiável, vital para a tomada de decisões de negócios, possibilitando obter vantagem competitiva. O Canadian Institute of Chartered Accountants (CICA) e o Instituto Americano de Contadores Públicos Certificados (AICPA), em 1999, definiram auditoria continua como,

uma metodologia que permite aos auditores independentes fornecerem garantias por escrito sobre qualquer assunto, para as 
quais o responsável pela gerência de uma entidade, utilizando uma série de relatórios de auditoria emitidos simultaneamente com, ou num curto período, após a ocorrência de eventos subjacentes (tradução própria).

Os procedimentos da auditoria contínua são realizados pelos auditores, entretanto, cabe aos gestores e aos auditores o monitoramento contínuo dos processos de negócios e controles internos visando garantir a eficiência e a eficácia das suas operações (Kuenkaikaew e Vasarhelyi, 2013). Desta forma, como processo complementar à auditoria contínua, adota-se o monitoramento contínuo para apoiar as tarefas de monitoramento de gestão. Neste contexto, o monitoramento contínuo é de responsabilidade dos gestores. Para a KPMG (2010), monitoramento contínuo é,

um mecanismo de feedback utilizado pela administração para assegurar que os controles operam conforme o projeto e as transações processadas como prescritas. Este método de monitoramento é de responsabilidade da administração e podem formar um componente importante da estrutura de controles internos (tradução própria).

A auditoria preditiva surge a partir da auditoria contínua cujos métodos fazem uma abordagem associando um olhar sobre os eventos passados com métodos de previsão e assim poder prever o resultado esperado no futuro. A auditoria de previsão objetiva focar seu olhar nos eventos passados e criar ajustes com base em mudanças ou erros que já ocorreram, desta forma, os auditores podem rapidamente detectar (ação preditiva) ou impedir (ação preventiva) irregularidades e anomalias.

Um processo de "auditoria contínua requer integridade e segurança na transferência de dados do sistema do cliente ao banco de dados do auditor, e que também requer a segurança da base de dados do auditor." (Moore et al., 2004 apud KHARGI, 2011, p. 26).

Segundo ORINGEL et al (2009 apud KHARGI, 2011, p. 31):

A tecnologia XBRL pode melhorar os processos de auditoria e monitoramento contínuos quando, aplicada no nível da transação, pode reduzir substancialmente o custo de aquisição de dados que toda organização necessita. Em um ambiente desprovido da tecnologia XBRL, a aquisição de dados precisos e confiáveis pela organização pode ser o passo mais desafiador e cro na implementação de auditoria contínua. Com a tecnologia XBRL totalmente integrada, permite-se que os dados, em nível de operação, possam ser definidos e marcados de forma única, de modo que eles podem ser lidos e analisados por qualquer sistema operativo em tempo real. A representação padronizada facilita a aquisição de dados mais eficientemente e confiável. Isto deve ser usado na esfera da entidade que analisa o risco do negócio, mitigando controle, eficiência operacional, cumprimento, e as avaliações de relatórios trimestrais, mensais, ou proxima de demandas em tempo real (tradução nossa). 
Neste cenário, trabalhos publicados por diversos autores que estão referenciados em KHARGI (2011) ratificam que a utilização da tecnologia XBRL contribui para a eficácia e eficiência dos processos de auditoria e monitoramento contínuos.

\section{Padronização do ambiente de coleta e manipulação de dados tributários sob a ótica da auditoria contínua: uma aplicação no projeto SPED brasileiro}

O projeto SPED foi instituído pelo Governo Federal do Brasil em 22 de janeiro de 2007 o qual foi definido, de acordo com o Sitio ${ }^{5}$ da Receita Federal do Brasil (2014), como

o instrumento que unifica as atividades de recepção, validação, armazenamento e autenticação de livros e documentos que integram a escrituração comercial e fiscal dos empresários e das sociedades empresárias, mediante fluxo único, computadorizado, de informações.

Desde a sua adoção surgem trabalhos focando seus pontos positivos assim como as dificuldades de sua adoção. Trata-se de um projeto que pretende ser um grande avanço tecnológico na relação governo e empresa com o emprego de recursos avançados da tecnologia de informação. Constata-se que esse projeto tem gerado profundas transformações nas áreas de tecnologia, fiscal e contábil das empresas. Na área contábil, seus efeitos começam por demandar a adoção de métodos contábeis modernos em detrimento aos adotados pela contabilidade tradicional. $\mathrm{Na}$ área de tecnologia impõe a necessidade de aperfeiçoamento contínuo das técnicas adotadas e do recurso humano alocado para o desenvolvimento e manutenção de software. Na área fiscal, a necessidade de dispor de informações que atendam aos requisitos de qualidade.

No momento do desenvolvimento deste trabalho, nove projetos compunham o SPED: ecd (Sped Contabil), efd icms ipi (Sped Fiscal), CT-e, NF-e, FCont, NFS-e, EFDContribuições, ECF e eSOCIAL (logo incorporado). Os projetos do SPED de acordo com o tipo de formato do arquivo gerado são mostrados na Figura 1. Quatro projetos têm os seus arquivos transacionais no formato XML (arquivo digitais trafegados). Os demais projetos têm os seus arquivos transacionais no formato texto ASCII (arquivos digitais periódicos).

\footnotetext{
${ }^{5}$ www.receita.fazenda.gov.br/legis/acao/decretos/2013/dec7979.htm 


\section{Projeto SPED}

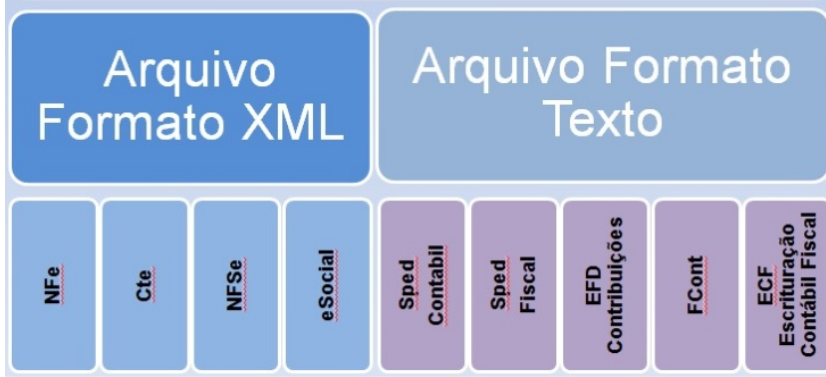

Figura 1: Composição do Projeto SPED

A seguir faz-se uma breve descrição de cada um desses projetos:

- $\quad$ ECD (Sped Contabil) - Tem por objetivo a substituição da escrituração em papel pela escrituração transmitida via arquivo, dos livros Diários, Razão, Balancetes Diários e Balanços;

- EFD ICMS IPI (Sped Fiscal) - Constitui-se de um conjunto de escriturações de documentos fiscais e de outras informações de interesse dos fiscos, bem como de registros de apuração de impostos referentes às operações e prestações praticadas pelo contribuinte;

- CT-e - Possui o intuito de documentar uma prestação de serviços de transportes;

- $\quad$ NF-e - Documenta uma operação de circulação de mercadorias ou prestação de serviços;

- FCont - É uma escrituração, das contas patrimoniais e de resultado, utilizando o conceito contábil de partidas dobradas;

- $\quad$ NFS-e - Documenta as operações de prestação de serviços.

- EFD-Contribuições - É escrituração do PIS e Cofins, nos regimes de apuração não-cumulativo e/ou cumulativo;

- $\quad \mathbf{E C F}$ - É a escrituração contábil fiscal, que apura o IRPJ e a CSLL.

- eSocial - É o sistema que unifica o envio de informações fiscais, previdenciárias e trabalhistas pelo empregador em relação aos seus empregados.

O SPED apresenta dois grandes desafios estruturais: a padronização eentre projetos e a múltipla representação de conceitos. A baixa padronização diz respeito aos dois formatos distintos para os arquivos transacionais e a diferentes modelos conceituais para a representação dos dados.

A ausência de um padrão único para os dados dificulta a integração e a interação entre os projetos; aumenta a complexidade e, consequentemente, o custo na implementação de rotinas voltadas para extração, análise, avaliação e auditoria dos dados; compromete o intercâmbio de informações entre os sistemas.

A repetição de representação de conceitos aparece seja na análise vertical dos projetos, a qual visa estabelecer comparações entre os conceitos dentro da estrutura de um projeto, ou na análise horizontal entre diferentes projetos, que objetiva estabelecer 
comparações entre os conceitos de dois ou mais projetos. Essa multiplicidade é consequência da ausência de um modelo de dados único e integrado para todos os projetos do SPED. A seguir é apresentada a metodologia utilizada para a eliminação de conceitos repetidos no projeto SPED.

\subsection{Metodologia para eliminação de conceitos repetidos no SPED}

O processo de padronização e identificação da multiplicidade de conceitos iniciou-se por uma análise visual e manual dos conceitos definidos nos projetos do SPED baseados em XML e ASCII, utilizando método próprio para correlacionar os conceitos. A partir da identificação da similaridade, representações repetidas de conceitos foram excluídas, mantendo-se apenas uma representação para cada conceito e utilizando nomenclatura padronizada para denominá-los.

Terminada a etapa de análise visual sobre os conceitos e com a eliminação manual da múltipla representação, foi criado um banco de dados relacional para utilizar um método de análise de similaridade automatizado, proposto na dissertação, desenvolvida no mestrado de Sistemas e Computação da Universidade Salvador (UNIFACS), intitulado “Avaliação de Similaridade entre Conceitos Representados pela XBRL ${ }^{6}$, de autoria de Marta Mesquita Mota Dunce e sob orientação do professor Paulo Caetano. O objetivo desta etapa da metodologia foi confirmar que não havia multiplicidade de representação para o mesmo conceito, ou seja, garantir a efetividade e eficiência da etapa anterior.

Concluída a análise de similaridade automatiza, foi executada uma validação por meio da criação de uma taxonomia baseada na tecnologia XBRL, sob a qual foi efetuada mais uma análise de similaridade, utilizando o método automatizado, cujo objetivo foi confirmar a exclusão de conceitos repetidos e a unicidade de cada conceito no dicionário proposto.

A metodologia usada para o desenvolvimento deste trabalho, i.e. a identificação de múltipla representação de conceitos no SPED e a criação da taxonomia XBRL para o SPED, está descrita em detalhes em http://tede.unifacs.br/tede/handle/tede/428.

A seguir é descrita a aplicação da metodologia para a eliminação da repetição de conceitos similares com diferentes representações no SPED, com a proposição de um modelo de dados único e, consequente, taxonomia XBRL para o SPED.

\subsection{Uma Proposta de padronização para o SPED}

Os dois fatores mencionados (baixa padronização e multiplicidade de conceitos) aumentam o grau de complexidade nos processos de análise de dados. A partir destas questões é proposto neste trabalho uma padronização para o projeto SPED por meio da tecnologia XBRL, de forma que viabilize o intercâmbio de informações financeiras e contábeis no ambiente web. Contempla-se o desenvolvimento de uma taxonomia específica para o projeto SPED visando à padronização e a eliminação da repetição de conceitos. Segundo Dunce et al. (2013), a padronização das informações fornece inúmeros benefícios. $\mathrm{O}$ uso de uma linguagem única para padronizar a comunicação entre as diversas entidades consumidoras de informações financeiras em formato eletrônico (empresas, filiais, holding, órgãos reguladores, etc.) facilita o intercâmbio de

\footnotetext{
${ }^{6} \mathrm{http}: / /$ tede.unifacs.br/tede/handle/tede/427

isys: Revista Brasileira de Sistemas de Informação (isys: Brazilian Journal of Information Systems) http://seer.unirio.br/index.php/isys/
} 
informações. Os custos de transformação da informação entre os diversos formatos, revalidação e correção de erros são eliminados com o uso de um padrão, que propicia economia de escala (Hoffman, 2006).

Sendo assim, a tecnologia XBRL, pelas características apresentadas na seção 2, apresenta-se como uma proposta a ser avaliada num esforço de padronização, para a substituição dos dois modelos de dados que atualmente compõem os projetos do SPED. Desta forma, a origem das informações passa a ser documentos XBRL contendo informações sobre as movimentações econômico/financeiras (vendas e aquisições de produtos e serviços) de uma entidade empresarial, gerados a partir de uma base de dados relacional do sistema ERP (Enterprise Resource Planning).

Para que isso ocorra propõe-se a criação de um modelo de dados baseado na taxonomia XBRL GL suportada por uma ontologia de domínio. A ontologia de domínio colabora para que os métodos de auditoria contínua (preventiva e preditiva) aplicados sobre os documentos XBRL possam capturar e analisar as informações, e sinalizar as incoerências, incorreções e necessidades de ajustes. Os procedimentos de auditoria poderiam garantir que somente os documentos XBRL auditados e aprovados possam ser disponibilizados para formalizar as transações a que se destinam. $O$ resultado seria a garantia de que o documento XBRL resultante (arquivo para transmissão para o órgão regulador) esteja validado antes de ser enviado ao órgão competente. A Figura 2 ilustra esse modelo proposto para o SPED.

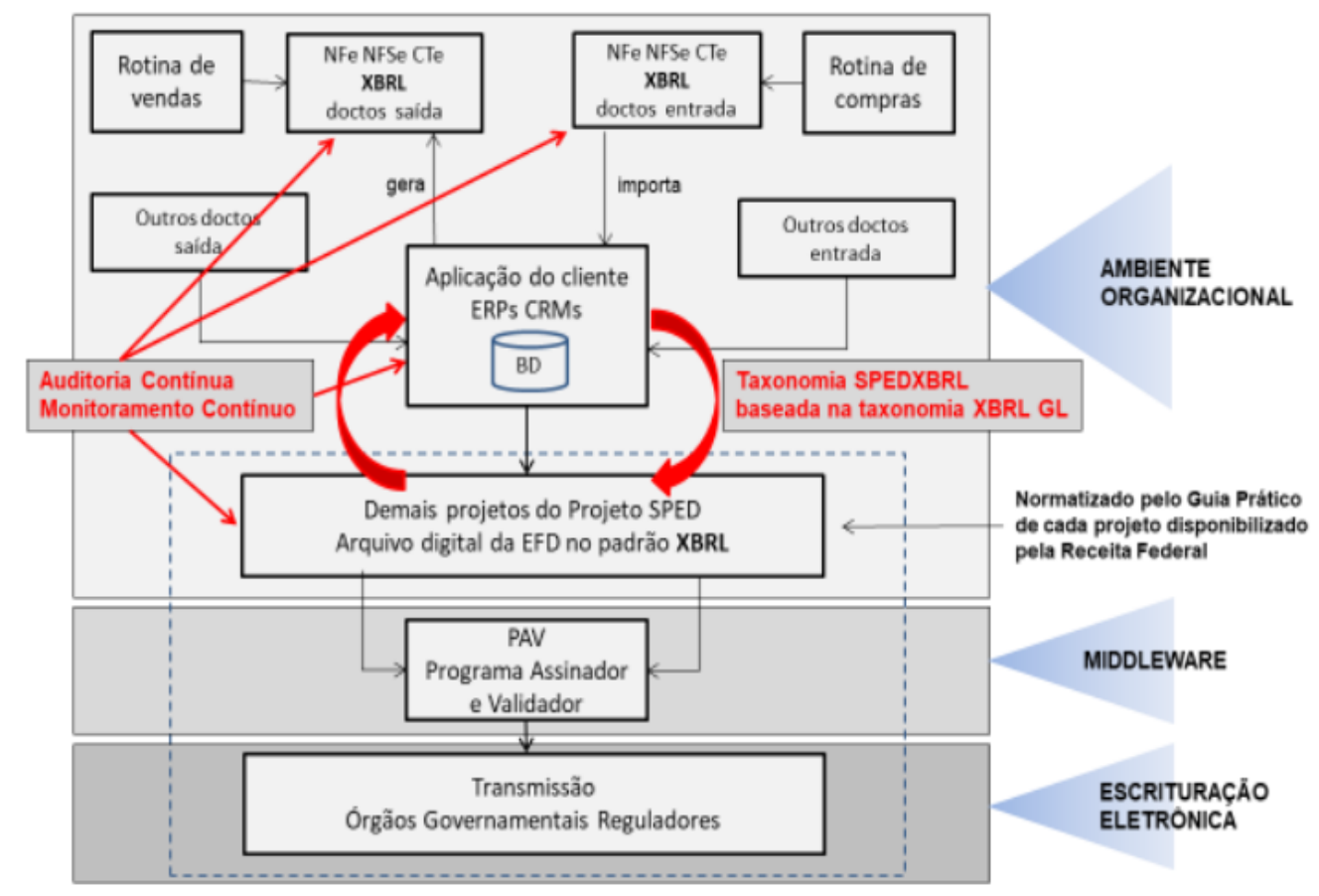

Figura 2: Modelo XBRL para o SPED

O modelo proposto contribuiria para o aumento da confiança e credibilidade dos dados, os quais são a base para a geração do documento XBRL que será transmitido ao fisco, no caso do SPED, através do PVA (Programa Validador e Assinador). Esse recurso 
é muito relevante na medida em que a auditagem antecipada dos dados atestaria sua integridade, evitando, desta forma, custos expressivos com autuações devido a inexatidão ou omissão de informações transmitidas. Implica afirmar que a redução das autuações e, consequente, diminuição dos custos de defesa jurídica fiscal contribuirão para a redução de custos.

A elaboração desse processo foi constituída por cinco fases: (i) processo de análise de similaridade entre conceitos representados nos projetos com arquivos digitais periódicos (padrão ASCII); (ii) processo de análise de similaridade entre conceitos representados nos projetos com arquivos digitais trafegados (padrão XML); (iii) confronto entre os conceitos dos projetos com arquivos padrão texto e os projetos com arquivos padrão XML; (iv) desenvolvimento de uma taxonomia XBRL para o SPED; e, (v) validação da proposta. Essas fases são discutidas a seguir.

\subsection{Análise de similaridade entre conceitos do SPED}

Foi realizado um mapeamento, para uma planilha eletrônica, de todos os conceitos envolvidos no projeto SPED, isto revelou um total de 5.065 conceitos catalogados. Nessa planilha foi feita uma classificação em ordem alfabética pela coluna denominada "conceito" que agrupou os conceitos semanticamente idênticos. Após essa etapa fez-se a análise semântica e funcional de cada conceito eliminando da planilha ordenada os conceitos similares. Como resultado apurou-se resultado final contendo 1.213 conceitos remanescentes. Entretanto, para corroborar os resultados obtidos, os 5.065 conceitos originais foram submetidos à análise de similaridade automatizada. A análise de similaridade de conceitos realizada neste trabalho revelou repetição de conceitos, confirmando os resultados obtidos pela exclusão de conceitos diretamente na planilha eletrônica.

O processo de análise de similaridade aplicado a este trabalho ocorreu em três etapas. Na primeira etapa, realizou-se uma análise sobre as estruturas conceituais dos projetos SPED que apresentam arquivos de integração em formato texto. A realização dessa etapa baseou-se nos manuais ${ }^{7}$ expedidos para Secretaria da Receita Federal do Brasil que normatizam as regras para a elaboração do arquivo digital de integração entre o fisco e o contribuinte.

A normatização técnica ${ }^{8}$ desses arquivos é composta por blocos, registros e campos. Após a tabulação dos conceitos que compõe a estrutura do arquivo procedeu-se a análise comparativa entre os conceitos de cada estrutura. Como resultado apurou-se duas situações: a repetição da representação de conceitos entre os blocos de um determinado projeto (análise vertical) e a repetição da representação de conceitos entre os projetos avaliados (análise horizontal). Essas duas situações revelaram que as relações entre os conceitos apresentavam relações similares do tipo 1:0, 1:1 e 1:n. O tipo 1:0 representam conceitos que não se replicam entre os blocos e entre os projetos. O tipo 1:1 representam conceitos que estabelecem uma única replicação. O tipo 1:n representam conceitos que se replicam tanto na análise horizontal quanto na vertical. Esta etapa é ilustrada na Figura 3.

\footnotetext{
${ }^{7}$ Guias Práticas para cada projeto do projeto SPED disponibilizados pela Secretaria da Receita Federal do Brasil no Sitio do Sped (http://www1.receita.fazenda.gov.br/Sped/)

${ }^{8}$ De acordo a documentação disponibilizada pelo Sitio de cada projeto do projeto SPED 


\begin{tabular}{|l|l|}
\multicolumn{2}{|c|}{ ASCII } \\
\begin{tabular}{|l|l|}
\hline PROJETO EFD-CONTRIBUIÇŌES \\
\hline \multicolumn{1}{|c|}{ REGISTROS } & CAMPOS \\
\hline & \\
\hline 0400 & DESCR_NAT \\
\hline A100:C100:C396:C500 & VL_DOC \\
\hline
\end{tabular}
\end{tabular}

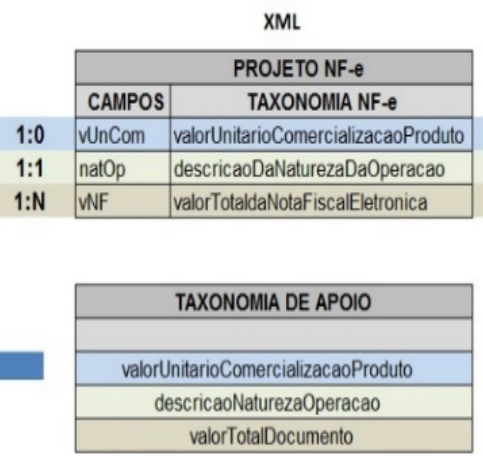

\begin{tabular}{|c|c|c|}
\hline & \multicolumn{2}{|c|}{ ASCII } \\
\hline & \multicolumn{2}{|c|}{ PROJETO SPED FISCAL - ICMS/IPI } \\
\hline & REGISTROS & CAMPOS \\
\hline 1:0 & & \\
\hline 1:1 & 0400 & DESCR NAT \\
\hline $1: \mathrm{N}$ & $\mathrm{C} 100 \mathrm{C} 300 \mathrm{C} 460 \mathrm{C} 50$ & VL. DOC \\
\hline
\end{tabular}

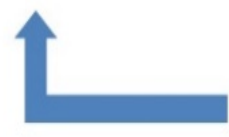
valorTotalDocumento

Figura 3: Sumario dos resultados de análise horizontal entre projetos do SPED

Para ratificar a proposta de padronização, realizou-se uma análise horizontal das estruturas conceituais entre dois projetos com arquivos transacionais distintos. Os projetos EFD-Contribuições e Sped Fiscal, que estão no padrão ASCII, enquanto que o projeto $N F$-e está no padrão XML. Nota-se, na Figura 3, que as relações entre a estrutura conceitual do projeto $N F$-e em relação aos outros dois projetos são idênticas àqueles resultados encontrados na análise horizontal, realizada somente entre os projetos padrão ASCII. A relação 1:0 indica que determinado conceito pertence somente ao projeto. A relação 1:1 indica que um conceito encontra um conceito equivalente em outros projetos. A relação 1:n indica que um determinado conceito encontra conceitos equivalentes em outros projetos ou dentro do mesmo projeto. $\mathrm{Na}$ análise horizontal, Figura 3, verifica-se que o elemento $v N F$ do projeto $N F$-e estabelece uma relação direta com o elemento $V L \_D O C$ presente nos projetos EFD-Contribuições e Sped Fiscal. Entretanto, o elemento $V L_{-} D O C$ pertence a vários registros distintos nos projetos de formato texto (análise vertical). Comprova-se, desta forma, a existência de repetição de conceitos com representações diferentes entre os projetos de formatos iguais ou distintos e em um mesmo projeto. Sendo assim, a utilização de um único elemento poderia ajudar na padronização do projeto SPED, por exemplo, utilizando um único elemento de taxonomia, denominado valorTotalDocumento, para representar o conceito "valor do documento".

Segundo Dunce et al (2013), a avaliação de similaridade é um processo que apoia a gestão de dados por ser utilizada em várias atividades relacionadas a essa disciplina. A avaliação de similaridade tem por objetivo classificar um conjunto de dados usando como critério a semelhança entre eles. Pode ser aplicada em atividades de limpeza ou integração de dados, na recuperação de dados e no controle de versões. A função de similaridade é comumente expressa com um número $n$ variando entre 0 e 1 . Quanto mais próximo de 1 reflete-se maior grau similaridade entre os conceitos comparados, sendo o valor 1 utilizado para representar conceitos absolutamente iguais.

A segunda etapa deste processo caracterizou-se pela análise automatizada de similaridade entre conceitos aplicada aos projetos com arquivos de integração baseados no padrão XML. Segundo Dunce et al. (2013), "a avaliação de similaridade é o processo de comparar dados com o objetivo de classificar a semelhança entres eles". Para obtenção dos resultados utilizamos a metodologia de Dunce et al. (2013), a qual agregou um conjunto de técnicas de análise de similaridade (e.g. técnica de QGrams como tokens, técnica de palavras como tokens, similaridade top-down e botton-up) incluindo nos 
resultados a combinação feita por meio de média aritmética e por meio da máxima similaridade.

Foram feitas duas análises automáticas de similaridade, a primeira aplicada sobre a base de dados sem o tratamento de similaridade. Isto para validar a primeira etapa. Após essa validação, o processo automatizado foi executado nos dados tratados, i.e., com a eliminação manual da multiplicidade de representação de conceitos.

Os resultados obtidos pelas análises vertical e horizontal sobre os dados sem o tratamento manual de similaridade foram semelhantes aos apurados na primeira etapa. Isto permite inferir que há necessidade de padronização do projeto SPED através de uma taxonomia única (taxonomia SPEDXBRL), visando, entre outros benefícios, a eliminação de repetição de conceitos representados distintamente.

Os resultados obtidos no processo da análise automatizada de similaridade, após a execução da primeira etapa, foram tabulados numa planilha eletrônica conforme ilustrado na Figura 4. Estipulou-se para a análise 7 (sete) faixas: a primeira faixa para resultados que retornaram valores iguais a 0.00 (zero) indicando conceitos distintos. A segunda faixa para resultados compreendidos entre 0,01 a 0,59 . A terceira faixa para resultados compreendidos entre 0,60 a 0,69. A quarta faixa para resultados compreendidos entre 0,70 a 0,79 . A quinta faixa para resultados compreendidos entre 0,80 a 0,89 . A sexta faixa para resultados compreendidos entre 0,90 a 0,99 e a sétima faixa para conceitos absolutamente iguais, isto é, retorno igual a 1 (um).

No grupo de resultados, ilustrados na Figura 4 pelo retângulo azul de número 1, para o registro da tabela cujo código é 13, o elemento efdContribuicoesOriginal foi confrontado com outros elementos do mesmo projeto, que usando todas as técnicas incluídas na metodologia de Dunce et al. (2013), gerou um total de 1.616 avaliações. Os resultados da análise são mostrados na área da tabela chamada RESULTADOS DA APURAÇÃO DA SIMILARIDADE. Para r=0,00 tem-se que 79,907\% dos demais elementos não possuem qualquer similaridade com efdContribuicoesOriginal e que $2,299 \%$, são totalmente similares, i.e. $\mathrm{r}=1,00$. Para o confronto entre dois projetos, por exemplo, para os projetos "nfe x ContribuicoesResumido", quinto registro da tabela, a análise é semelhante. Isto mostrou que ainda havia probabilidade de se encontrar conceitos remanescentes com representação múltipla.

\begin{tabular}{|c|c|c|c|c|c|c|c|c|c|c|}
\hline \multirow[b]{2}{*}{1} & \multicolumn{2}{|r|}{ PROJETO } & \multicolumn{7}{|c|}{ RESULTADOS DA APURAÇÃODA SIMILARIDADE } & \multirow{2}{*}{\begin{tabular}{|l|} 
NúMERO \\
DE AVALIAÇŌES
\end{tabular}} \\
\hline & COD & DESCRIÇÃO & $r=0.00$ & $0.01<=r>=0.59$ & $0.60<=r>=0.69$ & $0.70<=r>=0.79$ & $0.80<=r>=0.89$ & $0.90<=r>=0.99$ & $r=1.00$ & \\
\hline \multirow{6}{*}{ 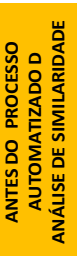 } & 13 & efdContribuicoes Original & $79,9070 \%$ & $17,6827 \%$ & $0,0791 \%$ & $0,0302 \%$ & $0,0015 \%$ & $0,0003 \%$ & $2,2992 \%$ & 1.616 \\
\hline & 8 & efdContribuicoesResumido & $74,0514 \%$ & $25,7595 \%$ & $0,0810 \%$ & $0,0923 \%$ & $0,0079 \%$ & $0,0011 \%$ & $0,0068 \%$ & 423 \\
\hline & 14 & efdFiscalOriginal & $85,0557 \%$ & $12,6316 \%$ & $0,1080 \%$ & $0,0722 \%$ & $0,0007 \%$ & $0,0007 \%$ & $2,1312 \%$ & 1.495 \\
\hline & 9 & efdFiscalResumido & $85,8504 \%$ & $14,0551 \%$ & $0,0399 \%$ & $0,0391 \%$ & $0,0065 \%$ & $0,0008 \%$ & $0,0081 \%$ & 496 \\
\hline & $6 \times 8$ & nfe x ContribuicoesResumido & $97,0717 \%$ & $2,9191 \%$ & $0,0020 \%$ & $0,0000 \%$ & $0,0007 \%$ & $0,0000 \%$ & $0,0066 \%$ & 784 \\
\hline & $6 \times 9$ & nfe $x$ FiscalResumido & $97,6404 \%$ & $2,3468 \%$ & $0,0045 \%$ & $0,0006 \%$ & $0,0011 \%$ & $0,0000 \%$ & $0,0067 \%$ & 857 \\
\hline DEPOIS & 12 & taxonomiaSpedXbrl & $27,5775 \%$ & $72,3847 \%$ & $0,0203 \%$ & $0,0128 \%$ & $0,0041 \%$ & $0,0006 \%$ & $0,0000 \%$ & 1.204 \\
\hline & & & & & & & de sim & Iridade & & \\
\hline
\end{tabular}

Por fim, na terceira etapa, após feita essa análise automatizada e excluídos os elementos com representação repetida, foi criada a taxonomia SPEDXBRL, que será discutida na Seção 3.4. Sobre essa taxonomia foi aplicada outra análise automatizada de 
similaridade. O resultado dessa última análise é visto na Figura 4 no retângulo vermelho de número 2. Observa-se que há concentração de resultados com $\mathrm{r}<0,59$, ou seja, podese afirmar que foram excluídos elementos com alta probabilidade de serem similares, nenhum resultado teve resultado $\mathrm{r}=1$.

\subsection{Taxonomia SPEDXBRL}

Para avaliar a eliminação da multiplicidade de representação de conceitos, foi desenvolvida uma taxonomia baseada na tecnologia XBRL (eXtensible Businnes Reporting Language). A taxonomia proposta para validar a eliminação de multiplicidade de representação de conceitos contempla todo o projeto SPED, com base no ano de 2015. Essa taxonomia foi inspirada na taxonomia do projeto $\mathrm{SICONFI}^{9}$ que está disponível no sitio da Secretaria do Tesouro Nacional ${ }^{10,11}$. O projeto SPED envolve outros órgãos públicos e a sociedade, por isso, há necessidade de se propor um modelo taxonômico que seja compatível com projetos de harmonização de dados, desenvolvidos por outros órgãos públicos. O SICONFI é o primeiro e único projeto no Brasil que utiliza esse padrão internacional.

Um dos princípios utilizados nos projetos XBRL é a padronização e harmonização dos dados fiscais e contábeis, por isso, a proposta deste dicionário está baseada na estrutura arquitetural do projeto SICONFI, com o objetivo de facilitar a integração e intercâmbio de dados entre esses órgãos. A taxonomia desenvolvida neste projeto contempla todo o projeto SPED. A arquitetura da taxonomia SPEDXBRL é composta por duas camadas: camada de definição e camada de relatórios. A Figura 5 mostra a estrutura da taxonomia com os seus módulos principais.

Nota-se que na camada de definição da taxonomia XBRLSPED encontra-se uma subcamada denominada "gl" que contêm as pastas referentes a taxonomia XBRL GL que são criadas e mantidas por entidades externas e que podem ser utilizadas pela taxonomia XBRLSPED. Na especificação da taxonomia XBRLSPED a camada de definição armazena os módulos XBRL GL que serão utilizados para representar os vários tipos de informações de detalhe. Neste contexto, essa camada contêm um arquivo XML Schema e os linkbases label, presentation e formula. Esses quatro elementos são criados para cada módulo utilizado e definidos a partir da versão original da taxonomia XBRL GL. No linkbase formula considera-se as validações necessárias para assegurar a qualidade desejada dos dados nos documentos de instância XBRL.

\footnotetext{
${ }^{9}$ SICONFI - Sistema de Informações Contábeis e Fiscais do Setor Público Brasileiro

${ }^{10}$ https://siconfi.tesouro.gov.br/siconfi/pages/public/taxonomia/taxonomia_list.jsf

http://www.tesouro.fazenda.gov.br/documents/10180/354141/Arquitetura_Taxonomia_Siconfi.pdf/84f 7d8e0-2ceb-4abb-8b24-d5bdec1c2f31

iSys: Revista Brasileira de Sistemas de Informação (isys: Brazilian Journal of Information Systems) http://seer.unirio.br/index.php/isys/
} 


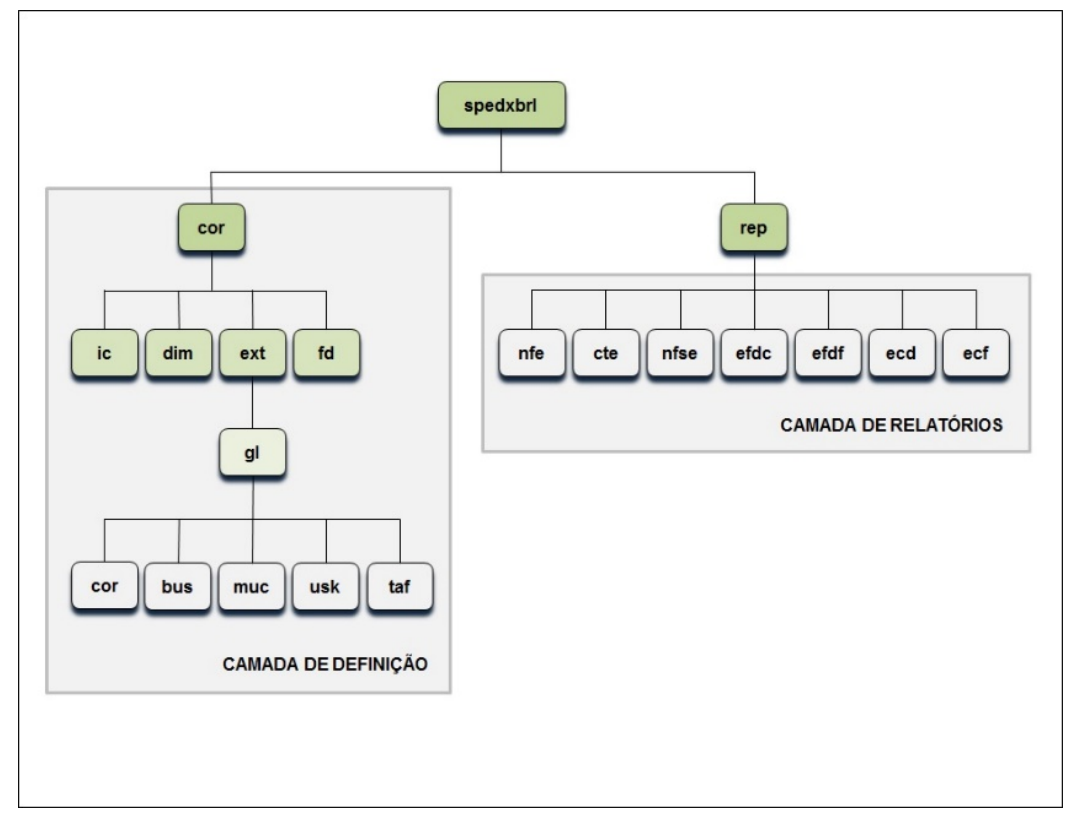

Figura 5: Arquitetura da Taxonomia XBRLSPED

$\mathrm{Na}$ camada de relatórios são os esquemas que definem os elementos específicos de cada projeto do SPED. Partindo dessas premissas a taxonomia XBRLSPED foi construída. A Figura 6 mostra um trecho da estrutura da taxonomia XBRLSPED.

\begin{tabular}{|c|c|c|c|c|c|c|}
\hline \multicolumn{7}{|l|}{ xad: element } \\
\hline name & id & type & substitutionGroup & abstract & nillable & xbrli:periodtype \\
\hline IndicadorTipoRegistro & xbrlsped-cor_JndicadorTipoRegistro & xbri:numerickemType & xbrilitiem & false & true & duration \\
\hline IndicadorTipoOperação & xbrlsped-cor_Jndicadơ TipoOperacao & xbri:numerickemType & xbrilitem & false & true & duration \\
\hline ValorTotalMercadoiasServicos & xbrlsped-cor_ValorTotalMercadoriasSenicos & xbril:monetaryltemType & xbrilitem & false & true & duration \\
\hline ValorBaseCalculolcms & xbrlsped-cor_ValorBaseCaloulolcms & xbril:monetaryttemType & xbrilititem & false & true & duration \\
\hline Valoricms & xbrisped-cor_Valoricms & xbri:monetaryltemType & xbrilititem & false & true & duration \\
\hline Valoripi & xbrisped-cor_Valorlpi & xbril:monetaryttemType & xbrilitem & false & true & duration \\
\hline ValorPis & xbrisped-cor_ValorPis & xbril:monetaryltemType & xbrilitem & false & true & duration \\
\hline ValorCofins & xbrisped-cor_ValorCofins & xbri:monetaryttemType & xbrifitem & false & true & duration \\
\hline CodigoContaAnalifca & xbrlsped-cor_CodigoContaAnalifca & xbril:numerciltemType & xbrilitem & false & true & durafion \\
\hline ValorTotal DebitoPeriodo & xbrisped-cor_ValorTotal DebitoPeriodo & xbri:monetaryltemType & xbrilitem & false & true & duration \\
\hline ValorTotalCreditoPeriodo & xbrisped-cor_ValorTotalCeditoPeriodo & xbril:monetaryltemType & xbrifitem & false & true & duration \\
\hline ValorLancamento & xbrisped-cor_ValorLancamento & xbril:monetaryltemType & xbrilitem & false & true & duration \\
\hline ValorParida & xbrlsped-cor_ValorParida & xbriitexttemType & xbriititem & false & true & duration \\
\hline IndicatorNaturezaParida & xbrlsped-cor_IndicadorNadurezaParida & xbrilitexttemType & xbrilitem & false & true & duration \\
\hline ValorSaldoFinal & xbrisped-cor_ValorSadoFinal & xbril:monetaryltemType & xbrilitiem & false & true & duration \\
\hline
\end{tabular}

\section{Figura 6: Extrato da Taxonomia XBRLSPED}

O principal objetivo da taxonomia XBRLSPED é contribuir para a padronização do projeto SPED e eliminar a repetição de conceitos. A taxonomia ilustrada na cor laranja foi criada para ser aplicada a todos os projetos com exceção dos projetos FCONT e ECD. Esses dois projetos estão voltados especificamente para a escrituração contábil. Para isso a taxonomia em azul especifica elementos necessários aos lançamentos de débito ou crédito, código de contas, etc., que são elementos voltados para a escrituração contábil. 
Os demais projetos estão voltados às atividades mercantis e apuração de tributos sobre essas operações.

Lembre-se que os projetos SPED FISCAL e EFD-Contribuições são projetos que apresentam seus arquivos transacionais no formato ASCII. Os projetos Nota Fiscal Eletrônica (NF-e), Conhecimento de Transporte Eletrônico (CT-e) e Nota Fiscal de Serviços Eletrônica (NFS-e) tem seus arquivos transacionais no formato XML. Nota-se, na Figura 7, que o trecho da taxonomia SPEDXBRL, voltada para os projetos destinados às atividades mercantis (NF-e, CT-e e NFS-e) e apuração de tributos (EFD-Contribuições e Sped Fiscal), contribui para solucionar os problemas de padronização e repetição de conceitos entre esses projetos. Observa-se que, com a definição de uma taxonomia única e baseada em XBRL, há um ganho semântico nos projetos que utilizam os dois tipos de representação de dados, ASCII e XML. Nos projetos o elemento "xbrlspedcor_indicadorTipoRegistro" pode ser associado à namespaces diferentes (i.e., namespace indicativo do tipo de projeto) permitindo que elementos dependentes hierarquicamente possam ser vinculados. Os projetos baseados em XML já detêm uma estrutura compatível com a taxonomia XBRL, facilitando sua compatibilização a este modelo de dados.

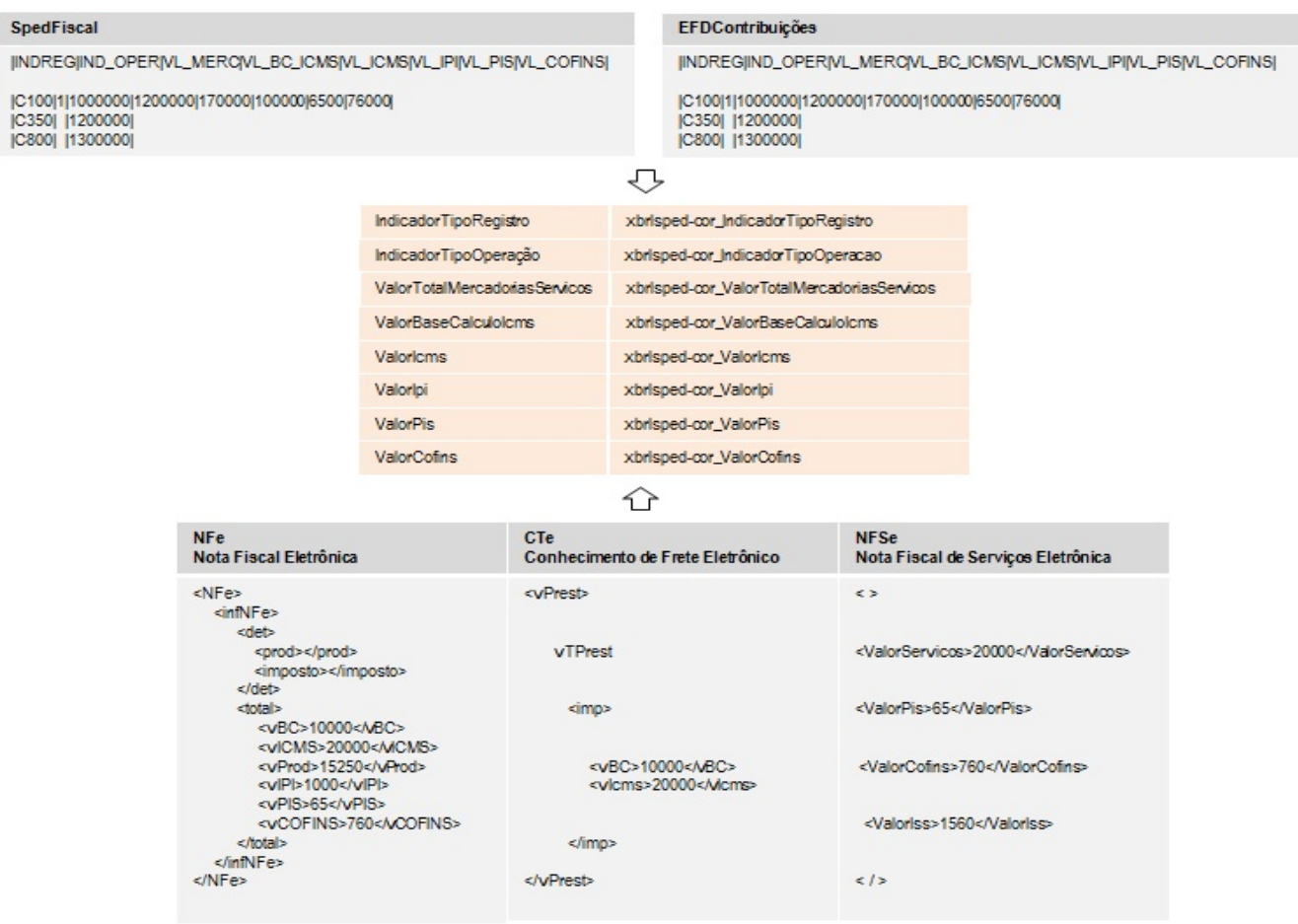

Figura 7: Taxonomia XBRLSPED e os projetos do SPED

Considerando-se as características particulares de cada projeto que compõe o SPED pode-se definir três etapas relacionadas ao seu ciclo da informação: (i) Inicial; (ii) Intermediária; e, (iii) Final. O Quadro 2 ilustra esse fluxo. 


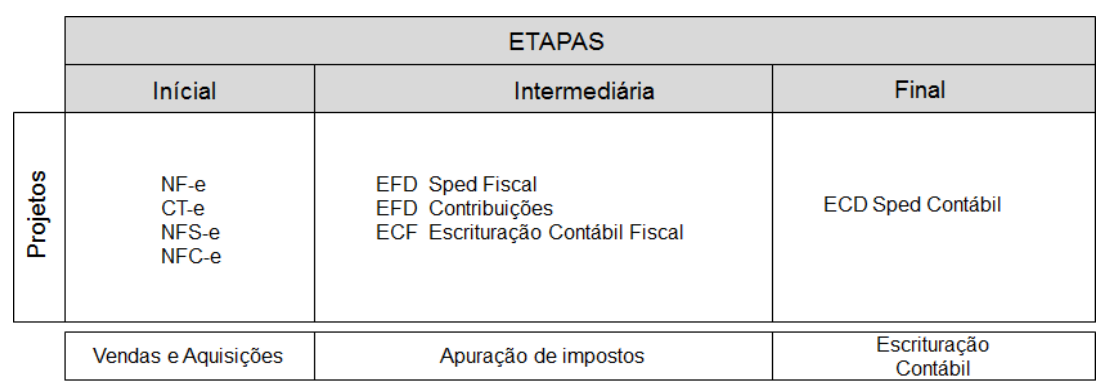

Quadro 2: Fluxo de informação no SPED

A etapa Inicial contempla os projetos voltados para registrar as operações mercantis de aquisição ou venda de mercadorias ou serviços. Essas operações geram a base de dados necessária para a apuração dos impostos a serem recolhidos ou compensados por uma empresa. Os projetos que compõe a etapa Intermediária se encarregam de registrar os débitos, créditos e o saldo da tributação apurada no período. A etapa Final congrega os projetos relacionados com as atividades de escrituração contábil de todas as operações contempladas desde o início do ciclo. Os projetos denominados ECD (Sped Contábil) e FCONT são os responsáveis pelos registros contábeis (partidas dobradas), pelos elementos que indicam apontamentos para os livros contábeis digitais (e.g. Diário, Balancetes, Demonstrações do Resultado do Exercício, Demonstrações Contábeis) e pelos elementos que formatam o plano de contas utilizado pela organização. A Figura 8 ilustra a relação existente entre os projetos do SPED da etapa Inicial à etapa Final.

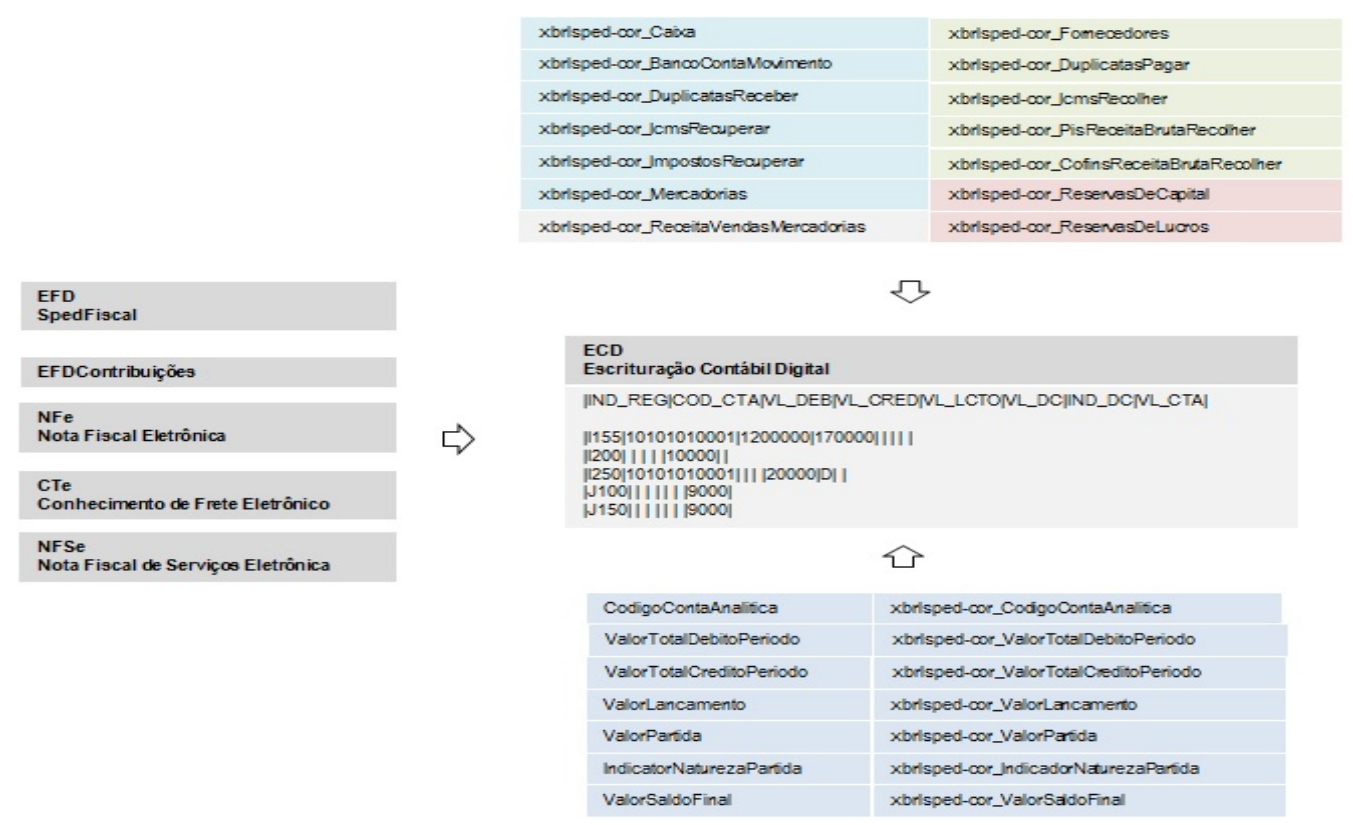

Figura 8: Projeto ECD-Escrituração Digital

Como a ECD (Escrituração Contábil Digital) é um dos projetos voltados para a escrituração contábil, verificam-se, na Figura 8, dois blocos de taxonomias. Na parte superior são as taxonomias voltadas para o plano de contas. Em azul as que representam as contas do Ativo; em bege as que representam as contas do Passivo; em rosa escuro as contas de Patrimônio; e, em rosa claro as contas de Resultado. Na parte inferior da Figura 8 são as taxonomias criadas para o projeto ECD. 
As informações que foram utilizadas para a geração dos arquivos transacionais dos demais projetos consolidam-se no ECD Sped Contábil como lançamentos que efetivam a escrituração contábil. Sendo assim, o elemento "xbrlspedcor_ValorTotalMercadoriasServicos" presente nos projetos das etapas inicial e intermediária poderá resultar num lançamento pelo elemento "xbrlspedcor_DuplicatasReceber" ou pelo elemento "xbrlsped-cor_DuplicatasPagar" dependendo do tipo da operação mercantil realizada (vendas ou aquisição). Da mesma forma, esse mesmo elemento poderá resultar num lançamento pelo elemento "xbrlspedcor_ValorLancamento" a débito ou a crédito, dependendo, também, do tipo da operação mercantil realizada. O esforço de padronização através da taxonomia SPEDXBRL, estendida da taxonomia do SICONFI e da XBRL GL, contribui para diminuir a complexidade, aumento do entendimento semântico dos elementos dos projetos e a eliminação da repetição conceitual.

Uma descrição detalhada desse processo de simplificação e padronização do SPED, assim como os arquivos da taxonomia XBRLSPED, podem ser vistos nas páginas web:

http://tede.unifacs.br/tede/handle/tede/428

https://sourceforge.net/projects/xbrlframework/files/XBRLSpedTaxonomy

\subsection{Auditoria Contínua no projeto SPED}

No Brasil a auditoria contínua ainda é embrionária, um dos motivos pode ser devido à falta de sua literatura em português; pela carência de auditorias e auditores; e, pelo fato de que poucos executivos, até mesmo das grandes empresas de auditorias, têm conhecimento sobre o assunto. Essas questões podem explicar a baixa adoção da autoria contínua pelos executivos brasileiros. Outras questões que se destacam são o custo de implementação; a falta de publicação dos casos de sucesso em auditoria contínua; e, a falta de auditores capacitados e aptos a auxiliar as empresas na implementação da auditoria contínua (Alles et. al., 2006). É nesse cenário que o projeto SPED vem sendo implantado. Essa ausência de cultura em auditoria contínua talvez explique parcialmente a menor necessidade de padronização do SPED.

Além do cenário acima exposto, em termos tecnológicos, um dos maiores entraves para a aplicação dos métodos de auditoria continua reside na complexidade em se extrair informações, em tempo real, para análise. Os métodos tradicionais mostram-se ineficazes para atender aos anseios de uma economia globalizada e em constante processo de transformação. Agilidade para viabilizar respostas dinâmicas, tomadas de decisões ágeis e bem fundamentadas, depende de acesso rápido às informações no momento em que acontecem. Rezaee et al. (2001) afirmam que "O principal benefício da utilização da auditoria contínua é a redução do custo de realizar um processo de auditoria na organização. A auditoria contínua permite aos auditores testar uma amostra maior das transações e dados dos clientes (até 100\%) de forma mais rápida e eficiente do que realizar testes de auditoria manuais em computador. A auditoria contínua pode reduzir a quantidade de tempo e custos que os auditores tradicionalmente gastam no exame manual de transações e saldos de contas. A auditoria contínua também pode aumentar a qualidade das auditorias financeiras, permitindo que os auditores se concentrem mais na compreensão dos negócios e da indústria de um cliente e na sua estrutura de controle 
interno". Isto significa planejar o momento futuro com informações atualizadas e com a menor latência possível.

A padronização torna-se um elemento fundamental para auditorias em tempo real não só nas informações que geram os arquivos assim como no conteúdo informacional contido nos arquivos transacionais. É interesse dos empresários, contabilistas e prestadores de serviços de tecnologia que as informações a serem transmitidas estejam devidamente conciliadas. Neste contexto, os projetos baseados em XML (NFe, CTe e NFSe) são os precursores dos desafios vindouros, já que esses projetos originam as informações de entrada dos demais projetos. A Figura 9 ilustra essa situação. Por isso, a possibilidade de auditar as informações dos projetos que originam as informações tem uma importância capital para que os demais projetos possam gerar seus arquivos transacionais já devidamente conciliados. Neste contexto, documentos XBRL que, no âmbito do projeto SPED, são os responsáveis pela geração de informações que irão compor a base de dados dos demais projetos, ao serem geradas ou importadas nesta fase inicial, serão validadas pela taxonomia SPEDXBRL e armazenadas em um banco de dados. Desta forma, os demais documentos XBRL a serem gerados pelos projetos responsáveis pelas escriturações serão documentos validados e construídos a partir da taxonomia SPEDXBRL. Os auditores, a partir da taxonomia SPEDXBRL, poderão rastrear, extrair, monitorar informações entre os documentos XBRL, assim como as armazenadas no banco de dados. Esse procedimento permite que organizações possam cumprir suas obrigações acessórias com maior segurança e confiança.

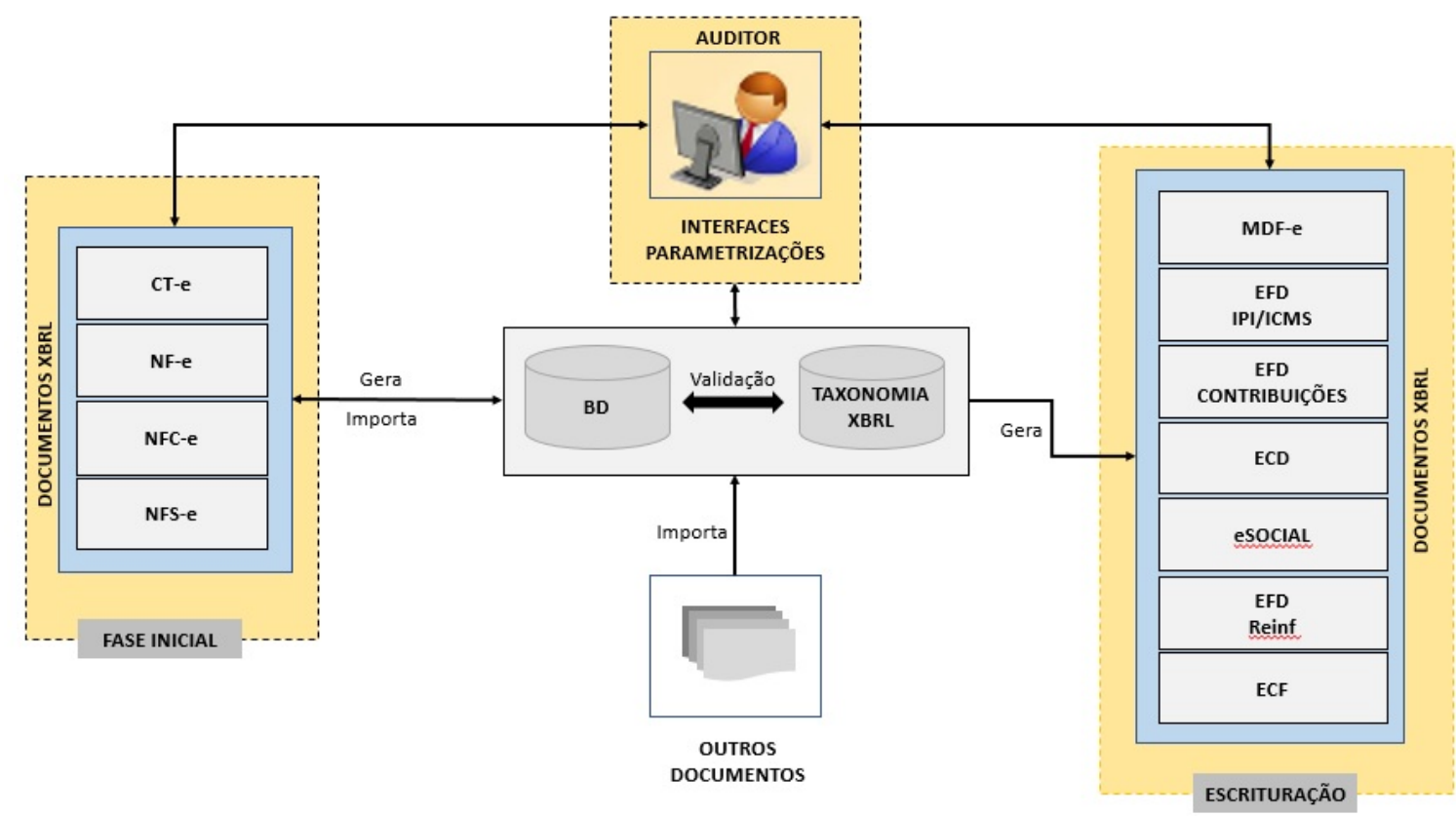

Figura 9 - Auditoria e monitoramento contínuo no ambiente SPED

O monitoramento contínuo torna-se uma ferramenta essencial para garantir a credibilidade do fluxo de informação dos módulos iniciais até a realização do seu registro contábil. Neste contexto, a taxonomia SPEDXBRL facilita a rastreabilidade da informação entre os projetos. A facilidade de rastreabilidade de uma informação é o maior ganho obtido pelo processo de padronização, pois, valores associados à exatidão semântica do conceito e o conceito associado à informação alvo do processo de auditoria e monitoramento contínuo garantem agilidade, flexibilidade e simplicidade nos processos 
de recuperação de dados. Além disso, as intervenções manuais através de interfaces complexas são substituídas por parametrizações menos complexas e com baixo nível de manutenibilidade. A condição essencial para que esse modelo atenda aos seus objetivos é a padronização do projeto SPED. Com a auditoria das informações de origem (documentos XBRL) essas poderão ser armazenadas em um banco de dados relacional da empresa já devidamente conciliadas e devidamente armazenadas em um repositório de documentos XBRL. Esse procedimento reduz drasticamente a possibilidade de que os demais arquivos transacionais sejam gerados com inconsistências. Entretanto, esses arquivos também deverão ser auditados de acordo com as regras estabelecidas para cada módulo antes de serem transmitidos ao fisco. Esse recurso permitirá que os arquivos transacionais, do início ao fim do processo, passem pelos processos de monitoramento e auditoria antes de serem arquivados ou transmitidos, garantindo a confiabilidade, coerência, integridade e qualidade das informações.

A auditoria contínua emerge neste trabalho, pois a padronização, de uma forma geral, cria um ambiente favorável para a aplicação dos seus métodos. Os ganhos significativos pela auditoria contínua com a padronização são, entre outros: (i) ambiente padronizado, favorecendo a identificação correta das informações; (ii) qualidade das informações, contribuindo para a auditoria dos dados e dos documentos gerados; (iii) eficiência e agilidade na apuração dos dados; (iv) reuso das informações; (v) facilidade na elaboração de relatórios de auditoria; e, (vi) tomada de decisões mais ágeis e eficientes. O cenário do SPED, tanto para a área de TI quanto para as áreas de negócios, incentiva investimentos em simplificação, padronização, auditoria e monitoramento contínuos; e, alerta para a necessidade de maior investimento em pesquisas nacionais nesta área, aprofundando a discursão, divulgando e criando um ambiente (de acordo com a realidade cultural, social e econômica brasileira) favorável à adoção da auditoria contínua. Essas ações podem contribuir para que a auditoria e monitoramento contínuos possam firmarse como um essencial instrumento de apoio às organizações no atendimento às exigências dos órgãos reguladores, às necessidades de entidades fornecedoras (e.g. financeiras, fornecedores), assim como, as suas próprias expectativas de gerenciamento e controle. $\mathrm{O}$ SPED traz uma nova realidade para o cotidiano das organizações brasileiras. As auditorias tributárias digitais que se caracterizam por realizar auditorias nos arquivos transacionais do SPED com o objetivo de aumentar a confiança e a qualidade das informações prestadas ao fisco, classificam esses arquivos como eventos: eventos diários, mensais e anuais. Por analogia, os eventos diários contemplam os projetos do SPED da etapa inicial; os eventos mensais estão relacionados aos projetos da etapa intermediária; e, os eventos anuais estão associados aos projetos da etapa final. Nesta circunstância, as organizações empresariais, demandam por necessidade de obter total controle sobre esses eventos. Um dos fatores determinantes para se atingir esse objetivo é o monitoramento contínuo. A Figura 10 ilustra essa discussão. 


\section{Auditorias Tributárias Digitais}

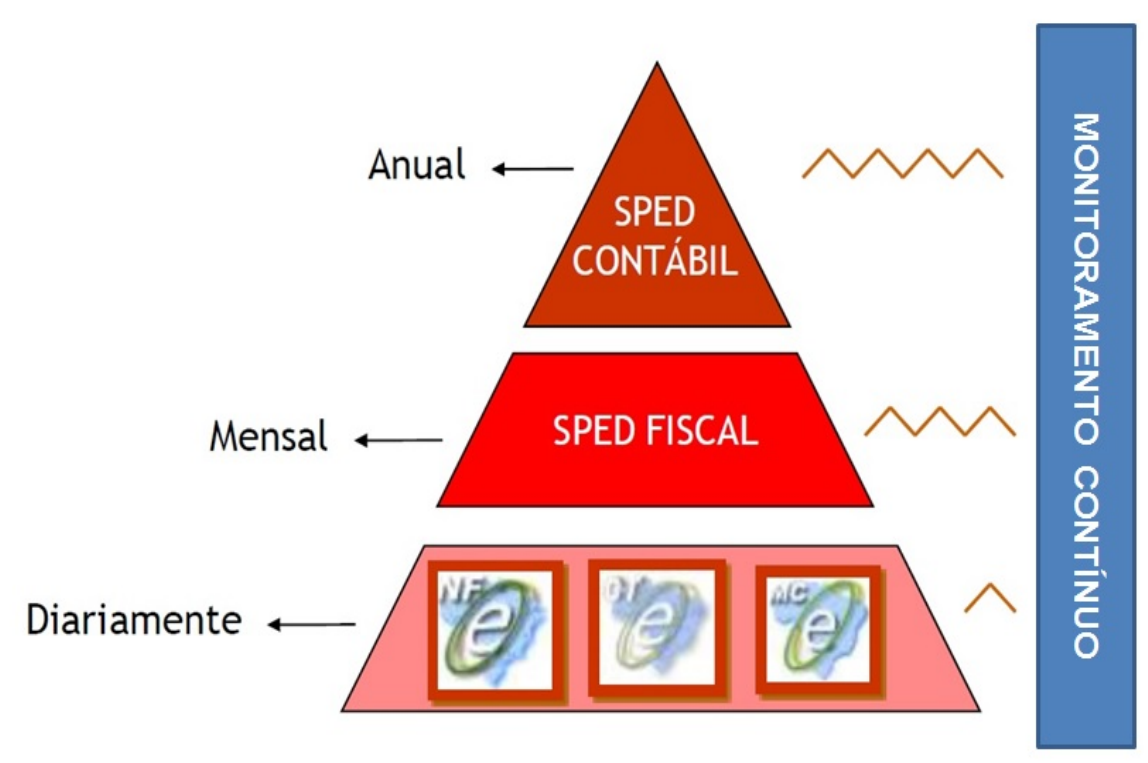

Figura 10 - Auditorias tributárias digitais

$\mathrm{Na}$ base da pirâmide encontram-se os projetos que compõem a etapa inicial que são os potenciais geradores de dados diários que servirão de carga para os demais projetos do SPED. A aplicação de um maior esforço de monitoramento contínuo sobre os resultados oriundos desta etapa poderá garantir a construção de uma base de dados mais confiável e consistente, trazendo ganhos de agilidade, confiabilidade, confiança e produtividade na geração dos arquivos transacionais nas duas últimas fases (intermediária e final). Cabe ressaltar que o monitoramento contínuo deve estar presente em todas as etapas. Isto garantirá a integridade de todos os projetos do SPED e permitirá que um ambiente padronizado contribua para que os processos de auditoria e monitoramento contínuos possam ser implantados sem entraves operacionais e gerenciais.

Uma das condições para que esse modelo atenda aos seus objetivos é a padronização do SPED. A adoção desse modelo diminuirá a complexidade do processo. Com a auditoria das informações de origem (documentos XBRL) essas poderão ser armazenadas em um banco de dados relacional da empresa já devidamente conciliadas. Da mesma forma, por serem documentos XBRL, serão armazenadas em um repositório de documentos XBRL. Isso já reduz drasticamente a possibilidade que os demais arquivos transacionais sejam gerados com inconsistências. Entretanto, esses arquivos também deverão ser auditados de acordo com as regras estabelecidas para cada projeto antes de serem transmitidos ao fisco. Esse recurso permitirá que os arquivos transacionais, do início ao fim do processo, passem pelos processos de auditoria antes de serem arquivados ou transmitidos. Desta forma, garante-se a confiabilidade, coerência, integridade e qualidade das informações.

\section{Conclusão}

A utilização da tecnologia XBRL é largamente difundida e indicada para o intercâmbio de informações financeiras e contábeis assim como suporte aos métodos de auditoria e 
monitoramento contínuos. A rigor, esses mecanismos se apresentam como alternativa aos métodos de auditoria tradicional já que a volatilidade do mercado exige, das empresas, reações imediatas à eventos inesperados. A sobrevivência das empresas, numa economia de tempo real, depende de respostas ágeis, porém fundamentadas para que possa contribuir para a busca de soluções. Para isso é necessário desenvolver mecanismos que favoreçam a extração, processamento e análise das informações empresariais, no menor tempo possível, entre o fato ocorrido e a resposta a ser dada. Entretanto, grande parte das informações importantes para uma tomada de decisão está armazenada em diferentes bancos de dados, despendendo alto custo, tempo e complexidade para extraí-las, conciliálas e analisá-las.

Os métodos de auditoria e monitoramento contínuos são concebidos para dar respostas imediatas a partir de análise, em tempo real, das informações. Desta maneira, o uso da tecnologia XBRL auxilia essa tarefa através da extração de informações de uma base de dados modelada com o suporte de uma taxonomia para o domínio da atividade empresarial. A tecnologia XBRL consolidou-se como uma ferramenta adequada para o intercâmbio de informações contábeis, financeiras e não financeiras no ambiente web. Essa tecnologia consolidou-se com as recentes crises mundiais provocadas pelas fraudes financeiras que assolaram o mundo corporativo, em razão de ser capaz de criar mecanismos que ajudem a mitigar as crises através da especificação de um padrão mundialmente reconhecido para a troca de informações entre as organizações contribuindo para uma maior transparência nas relações de mercado.

Diante dessas considerações é proposto neste trabalho a utilização de um modelo de dados baseado na tecnologia XBRL para realizar a padronização do projeto SPED brasileiro. A criação de uma taxonomia, denominada SPEDXBRL, estendida das taxonomias XBRL GL e do SICONFI, contemplando todos os projetos que compõe o projeto SPED, irá auxiliar na resolução dos desafios a serem enfrentados no projeto: a baixa padronização e a multiplicidade de representação de conceitos. O cenário atual do SPED dificulta a implantação de um processo de uma auditoria nos arquivos transacionais que são transmitidos aos órgãos reguladores. Os métodos de auditoria tradicional não devem ser aplicados nesse contexto devido à alta latência temporal entre o fato gerador, a sua escrituração contábil e análise.

Por se tratar de projetos que têm como finalidade informar aos órgãos competentes as apurações de tributos e registros contábeis o fator tempo está intimamente ligado ao calendário fiscal de apuração e apresentação das informações. Por isso, há necessidade de adoção dos métodos da auditoria contínua, por estarem em sintonia com a análise das informações em tempo real. Neste cenário, a padronização do projeto SPED pelo modelo de dados baseado em XBRL GL facilita os processos de auditoria contínua, assim como a adoção de mecanismos ligados a contabilidade moderna. Destarte, tornam-se mais ágeis os processos de extração, conciliação e análise de informações para a tomada de decisão por parte dos gestores. Concluímos desta forma, que a tecnologia XBRL contribui para a transformação das áreas contábeis e financeiras das organizações, no âmbito mundial, dando transparência e confiabilidade nas informações que são trocadas pelos atores pela rede mundial corporativa.

Este trabalho não esgota o tema embora aponte a possibilidade de padronização e simplificação do SPED e os ganhos oriundos desse esforço de padronização para a sociedade brasileira. Como trabalhos futuros, dada à limitação deste trabalho, pode-se 
estender a sua essência para a Comissão de Valores Mobiliários (CVM), Banco Central, SUSEP (Superintendência de Seguros Privados) e Projeto SICONFI da Secretaria do Tesouro Nacional, num esforço mais amplo em prol de empregar a tecnologia XBRL numa padronização global dos diversos órgãos reguladores e fiscalizadores do sistema financeiro nacional.

\section{Referências}

Alles, Michael G.; Tostes, Fernando; Vasarhelyi, Miklos A.; Riccio, Edson Luiz. (2006) "Continuous auditing: the USA experience and considerations for its implementation in Brazil". Journal of Information Systems and Technology Management, Vol. 3, No. 2, p. 211-224. ISSN online: 1807-1775.

Amrhein, Denise Guithues. (2009) "REA and XBRL GL: Synergies for the 21st Century Business Reporting System". Disponível em <http://www.uhu. es/ijdar/10.4192/1577-8517-v9_5.pdf>, Acesso em: 25 de janeiro de 2013.

Ballou, B; Heitger, D; Landes, C. (2006) “The Future of Corporate Sustainability Reporting: A Rapidly Growing Assurance Opportunity". Journal of Accountancy. 202 (6): $65-74$.

Chen, Ruey-Shun; Sun, Chia-Ming. (2007) "A collaborative continuous auditing model under service-oriented architecture environments". 6th WSEAS International Conference on e-activities, Tenerife, Spain.

Coderre, David. (2005) "Continuous auditing: implications for assurance, monitoring and risk assessment”. Global Technology Audit Guides (GTAG). Florida: IIA.

Cohen, Eric E. XBRL in Tax and Government. Disponível em $<$ http://www.xbrl.org/GLKeyFeatures/GL_WebSeminar_LutesCohen_051215.pdf>, Acesso em: 08 de outubro de 2012.

Dipiazza, Sam; Eccles, Robert G. Necessária reforma global do corporate reporting para restaurar a confiança pública nos mercados de capitais. Disponivel em: <http://www.pwcglobal.com/pt/por/about/pressrm/info_media/build-ingpt.html/>. Acesso em: 08 jun. 2004.

Dunce, Marta Mesquita Mota; Silva, Paulo Caetano da; Viana, Sidney. (2013) "Similarity Evaluation on XBRL Concepts". Proceedings of the Iadis International Conference www/Internet 2013, Fort Worth, Texas, USA, October 22-25, 2013. ISBN: 978-9898533-16-6.

Garbellotto, Gianluca. (2009) "Walking Through the SRCD PWD2 Sample Instances". Available at <http://www.xbrl.org/int/gl/2009-05-12/SRCD-PWD2-Walkthrough2009-05-12.pdf>.

Geron, Cecília Moraes Santostaso; Finatelli, João Ricardo; Faria, Ana Cristina De; Romeiro, Maria do Carmo. (2011) "SPED - Sistema Público de Escrituração Digital: Percepção dos contribuintes em relação os impactos de sua adoção". Revista de Educação e Pesquisa em Contabilidade, v.5, n.2, p.44-67, ISSN: 1981-8610.

Guerra, Márcia R. (2007) “Governança de TI com COBIT”. São Paulo: TIEXAMES. Disponível em: <http://www .tiexames.com.br/ensino/home.php>. Acesso em: 20 ago. 2008. 
Guimarães, André Sathler \& Johnson, Grace. (2007) "Administração em tempo real: Sistemas de informação". $1^{\circ}$ ed. Rio de Janeiro: Qualitymark, p.12-13.

Hoffman, C. (2006) “Financial Reporting Using XBRL: IFRS on US GAAP” Edition 1. Lulu.com.

Khargi, Kavita B. (2011) "The internal use of XBRL for continuous auditing purpose". Master Thesis Economics \& ICT, Erasmus Universiteit Rotterdam, Roterdã.

Kuenkaikaew, Siripan; Vasarhelyi, Miklos A. (2013) "The predictive audit framework". The International Journal of Digital Accounting Research, v.13, p. 37-71.

KPMG. (2010): "What is Driving Continuous Auditing/Continuous Monitoring Today?" White paper KPMG LLP.

Luciano, José Geraldo; Silva, Paulo Caetano da. (2014) “A data model for SPED based on XBRL GL". 11th Internacional Conference on Information Systems and Technology Management - CONTECSI, São Paulo, Brasil.

Peres, Clovis Belbute. (2015) "Inovações e desafios do Sistema Público de Escrituração Digital (SPED)". Revista do Conselho Federal de Contabilidade do Rio Grande do Sul, $\mathrm{n}^{\circ} 24$. Porto Alegre.

Portal SPED. Receita Federal do Brasil. Disponível em: <http://www1.receita.fazenda.gov.br/Sped/>. Acesso em: 01 ago. 2013.

Rezaee, Zabihollah; Elam, Rick; Sharbatoghlie, Ahmad. (2001) "Continuous auditing: the audit of the future". Managerial Auditing Journal, 16/3, p. 150-158, MCB University Press. ISSN 0268-6902.

Riccio, Edson; Sakata, Marici; Moreira, Orandi; Quoniam, Luc. (2006) "Introdução ao XBRL - nova linguagem para divulgação de informações empresariais pela internet". Ci. Inf., Brasilia, v.35, n.3, p. 166-182.

SILVA, Paulo Caetano da; Silva, Luiz Gustavo Cordeiro da; Júnior, Ivanildo José de Souza Aquino. (2006) "XBRL Extensible Business Reporting Language Conceitos e Aplicações". $1^{\circ}$ ed. Rio de Janeiro: Editora Ciência Moderna.

SARBANES-OXLEY. (2002) "The Sarbanes-Oxley Act”. Washington: Congress of the United States of the America. Disponível em: <http://www.law.uc.edu/CCL/SOact/soact.pdf>. Acesso em 20 ago. 2008.

Vasarhelyi, M. A; Halper, F.B. (1991) "The continuous audit of online systems". Auditing: A Journal of Practice and Theory, v. 10 n. 1, pp. 110-125, 1991.

Ye, Huanzhuo; Chen, Shuai; Gao, Fang. (2008) "On Application of SOA to Continuous Auditing”. WSEAS TRANSACTIONS on COMPUTERS. Issue 5, Volume 7. ISSN: $1109-2750$. 